\title{
Impactos Econômicos da Introdução do Milho Bt11 no Brasil: uma abordagem de equilíbrio geral inter-regional
}

\author{
Andressa Rodrigues Pavão ${ }^{1}$ \\ Joaquim Bento de Souza Ferreira Filho²
}

Resumo: Este trabalho analisa os impactos econômicos da adoção do milho Bt11 no Brasil, bem como as consequências da proibição deste cultivo apenas no Paraná, caso a lei estadual no 14.162/03 entrasse em vigor. Para tal, utiliza-se um modelo computável de equilíbrio geral inter-regional, calibrado para 2001, simulando a redução de inseticida, mão de obra, combustível e lubrificantes, bem como o aumento de produtividade observado em lavouras de milho Bt11. Ao analisar a adoção nas regiões brasileiras "tecnificadas", observa-se o deslocamento de estoque de capital e mão de obra de todas as regiões para o Sul do País. Considerando-se que apenas o Paraná não adota milho Bt11, observa-se que tanto a mão de obra quanto o estoque de capital se deslocam do Sul e Sudeste para o Centro-Oeste do Brasil. Os resultados mais expressivos ocorrem no próprio estado do Paraná, onde não apenas o setor de milho, como também os setores a jusante perdem competitividade, reduzindo o nível de atividade, emprego e consumo das famílias. De forma geral, os efeitos da adoção do milho Bt11 são transmitidos ao longo da sua cadeia produtiva, gerando aumento do PIB, das exportações e do consumo das famílias, sendo mais expressivos nos setores e regiões diretamente relacionados com a cadeia de comercialização do milho, tais como os de criação animal e carnes, localizados, em sua maioria, no Sul do País.

Palavras-chave: milho Bt11, impactos econômicos, análise regional, modelos de equilíbrio geral.

Abstract: This study aims to analyze the economic impacts of the adoption of Bt11 corn in Brazil, as well as the consequences of the prohibition of the cultivation only in the Paraná state, if the state law number 14.162/03 would start to be active. For this purpose, an inter-regional general equilibrium computable model is used, gauged for

1 Doutoranda em Economia Aplicada, Escola Superior de Agricultura "Luiz de Queiroz", Universidade de São Paulo. E-mail: arpavao@esalq.usp.br

2 Professor Titular, Escola Superior de Agricultura "Luiz de Queiroz", Universidade de São Paulo. E-mail: jbsferre@esalq.usp.br 
2001, simulating the reduction of insecticide, labor force, fuel and lubricants, as well as the increase in the yield observed in crops which use Bt11 corn. When the adoption of Bt11 corn in "technified" Brazilian regions is analyzed, the stock of capital and labor force moves from all regions to the South of the country. Taking into account that only Parana state does not adopt the Bt11 corn, it is observed that both the labor force and the stock of capital move from the South and the Southeast to the Central-Western region of Brazil. The most expressive result takes place in the Parana State, where not only the corn sector, but also downstream sectors lose competitiveness, reducing the level of activity, employment and household consumption. In general terms, the effects of the adoption of the Bt11 corn are transferred along its supply chain, increasing GDP, exports and household consumption. Results are more expressive in sectors and regions directly related to the corn supply chain, such as animal raising and meat, mostly located in the South of the country.

Key-words: Bt11 corn, economic impacts, regional analysis, general equilibrium models.

\section{Classificação JEL: Q16.}

\section{Introdução}

A comercialização de produtos geneticamente modificados (GM) começou em 1996. Desde então, o cultivo de lavouras GM tem aumentado de forma surpreendente. Em 2007, foram plantados 114,3 milhões de hectares com lavouras GM por cerca de 55 milhões de produtores em 23 países, o que corresponde a $8 \%$ dos 1,5 bilhão de hectares de terras cultiváveis no mundo (JAMES, 2007).

A taxa de adoção de lavouras GM depende do produto analisado. Em alguns casos, os benefícios obtidos são tão elevados que a tecnologia é disseminada rapidamente entre as diversas regiões produtoras. Contudo, como ainda não existe um mercado regulador forte para diferenciar o produto GM do convencional, produtores que não o adotam acabam perdendo parte do lucro, visto que poderiam produzir mais com um custo inferior, utilizando a mesma área.

No Brasil, a primeira cultura GM aprovada foi a da soja RR, em 2003/04. A soja RR teve grande aceitação entre produtores brasileiros e, desde 2006, posicionou o País como o terceiro maior produtor de cultivos GM, atrás apenas dos Estados Unidos e da Argentina. Em 2007, a área cultivada com produtos GM no Brasil foi de 15 milhões de hectares, sendo 14,5 milhões de soja e 500 mil de algodão (JAMES, 2007). Dados de 2008 do IBGE (Instituto Brasileiro de Geografia e Estatística) sobre área plantada mostram que a taxa de adoção da soja GM é de $70 \%$, enquanto a do algodão, de $44 \%$.

Diante da grande adoção da soja GM, o País vem apresentando novos desdobramentos na biotecnologia. Em 2005, o plantio de algodão foi liberado, 
e em 2007, depois de quase 10 anos tramitando na Justiça, três variedades de milho GM foram liberadas. Convém ressaltar que, em termos mundiais, o milho GM foi liberado para comercialização pela primeira vez em 1996, nos EUA.

Devido à grande importância do milho para diversos setores, este trabalho tem como foco investigar os impactos econômicos causados pela adoção do milho GM em toda sua cadeia produtiva, principalmente nos setores a jusante, no Brasil e nos estados. No entanto, analisar todos os 27 estados brasileiros seria desnecessário, além de cansativo, e, portanto, opta-se por apresentar nos resultados as cinco macrorregiões brasileiras (Norte, Nordeste, Centro-Oeste, Sudeste e Sul) e o estado do Paraná, pois além de ser o maior produtor de milho do Brasil, é o objeto de estudo deste trabalho.

\section{Importância econômica do milho para o Brasil}

A demanda mundial por milho vem aumentando nos últimos anos, impulsionada pelo crescimento econômico dos países asiáticos e pela utilização do cereal nos Estados Unidos para a produção de etanol. Além disso, o consumo interno também tem aumentado de forma considerável em decorrência do crescimento do setor de carnes, mais especificamente, de aves e suínos.

A importância do milho no Brasil é ampla, primeiro porque sua produção ocorre tanto em pequenas propriedades, cuja finalidade é a subsistência, quanto em grandes extensões de terras para abastecer o mercado; segundo, porque sua importância nutricional torna-o amplamente utilizado, não apenas na alimentação humana, mas principalmente em ração animal.

O mercado de milho é promissor para os próximos anos, pois o crescimento da demanda gera expectativas no aumento do preço e incentiva a produção brasileira. De acordo com dados da Conab (Companhia Nacional de Abastecimento) de 2008, na safra 2007/08 foram plantados cerca de 14,2 milhões de hectares de milho, o que produziu aproximadamente 51 milhões de toneladas.

Em 2006, os maiores importadores de milho brasileiro foram o Irã (43\%), a Espanha (19\%) e a República da Coréia (19\%) (BRASIL, 2008). Historicamente, os EUA e a Argentina são os maiores exportadores de milho. O Brasil e a China alternam entre o terceiro e o quarto lugar no ranking das exportações.

Apesar de as exportações de milho do Brasil estarem aumentando nos últimos anos, a grande importância é para o consumo interno, notadamente para a produção animal. Nesse sentido, dados do Ministério das Relações Exteriores (BRASIL, 2008) apontam que, em 2006, o Brasil foi o maior exportador de carnes de aves, representando $25 \%$ do valor total das exportações, seguido pelos EUA, com 18\%. Os países que mais adquiriram carne de aves brasileiras foram o Japão (16\%), União Européia (16\%), Arábia Saudita (12\%), Hong Kong (8\%) e Federação Russa (7\%) (BRASIL, 2008). 
O Brasil também se destaca como um dos principais exportadores mundiais de carne suína, com aumento nas exportações em relação à década de 90 . Em 2006, os principais importadores de carne suína foram os países asiáticos (BRASIL, 2008).

Ao analisar ogrande potencial da produção de milho no Brasil esua importância como insumo para diversos outros setores, verifica-se que é fundamental o investimento em novas tecnologias capazes de aumentar a produtividade e reduzir os custos. Uma das alternativas propostas é a intensificação da produção de milho GM, uma vez que isso, em diversos países, tem proporcionado benefícios como o aumento na produtividade e a redução nos custos.

A partir dessa análise, algumas questões relevantes surgem: quais seriam os ganhos para os diversos setores da economia brasileira se o País adotasse essa nova tecnologia? Quais os estados mais beneficiados? Haveria mudanças nos agregados macroeconômicos?

\section{Metodologia}

Para analisar os impactos econômicos da adoção do milho Bt11 no Brasil, um modelo multirregional do tipo bottom-up, estático, denominado TERM-BR, é utilizado, pois consegue analisar os impactos sobre a economia do País sem perder os detalhes regionais e setoriais.

Diversos trabalhos realizados no Brasil têm utilizado uma adaptação do modelo TERM ${ }^{3}$ para analisar impactos regionais. Entre eles, pode-se citar Santos (2006), Fachinello (2008) e Domingues, Magalhães e Faria (2009).

O TERM-BR consiste em um modelo do tipo Johansen, em que as estruturas matemáticas são representadas por um conjunto de equações linearizadas e as soluções são obtidas na forma de taxas de crescimento (variação percentual). A preferência pelo modelo TERM ocorre porque demanda menor quantidade de dados devido às hipóteses facilitadoras, sendo a principal diferença a combinação única de origens para todos os usuários de um determinado produto em uma região.

As características do modelo TERM encontram-se no trabalho de Horridge, Madden e Wittwer (2005), e as modificações realizadas para criar o TERM-BR podem ser encontradas nos trabalhos de Santos (2006) e Fachinello (2008).

Porém, vale ressaltar algumas importantes características do modelo utilizado. O diagrama apresentado pela Figura 1 descreve quatro níveis fundamentais para a escolha da origem do produto a ser consumido, indicando várias possibilidades de substituição que são permitidas pelo modelo. Embora o exemplo contemple

3 The Enormous Regional Model (HORRIDGE, MADDEN e WITTWER, 2005), denominado TERM consiste em um modelo aplicado de equilíbrio geral inter-regional estático, do tipo bottom-up. 
apenas a demanda por milho em grão usado pela indústria de aves vivas no Paraná, o mesmo aplica-se para outras commodities, usuários e regiões.

Por meio de uma função CES as diversas regiões de origem são captadas. A elasticidade de substituição entre as origens domésticas pode variar de zero, como nos setores de serviços e de construção civil, a 7,6 para os setores produtores de carne.

Figura 1. Esquema de origem de fluxo para atendimento da demanda no TERM-BR.

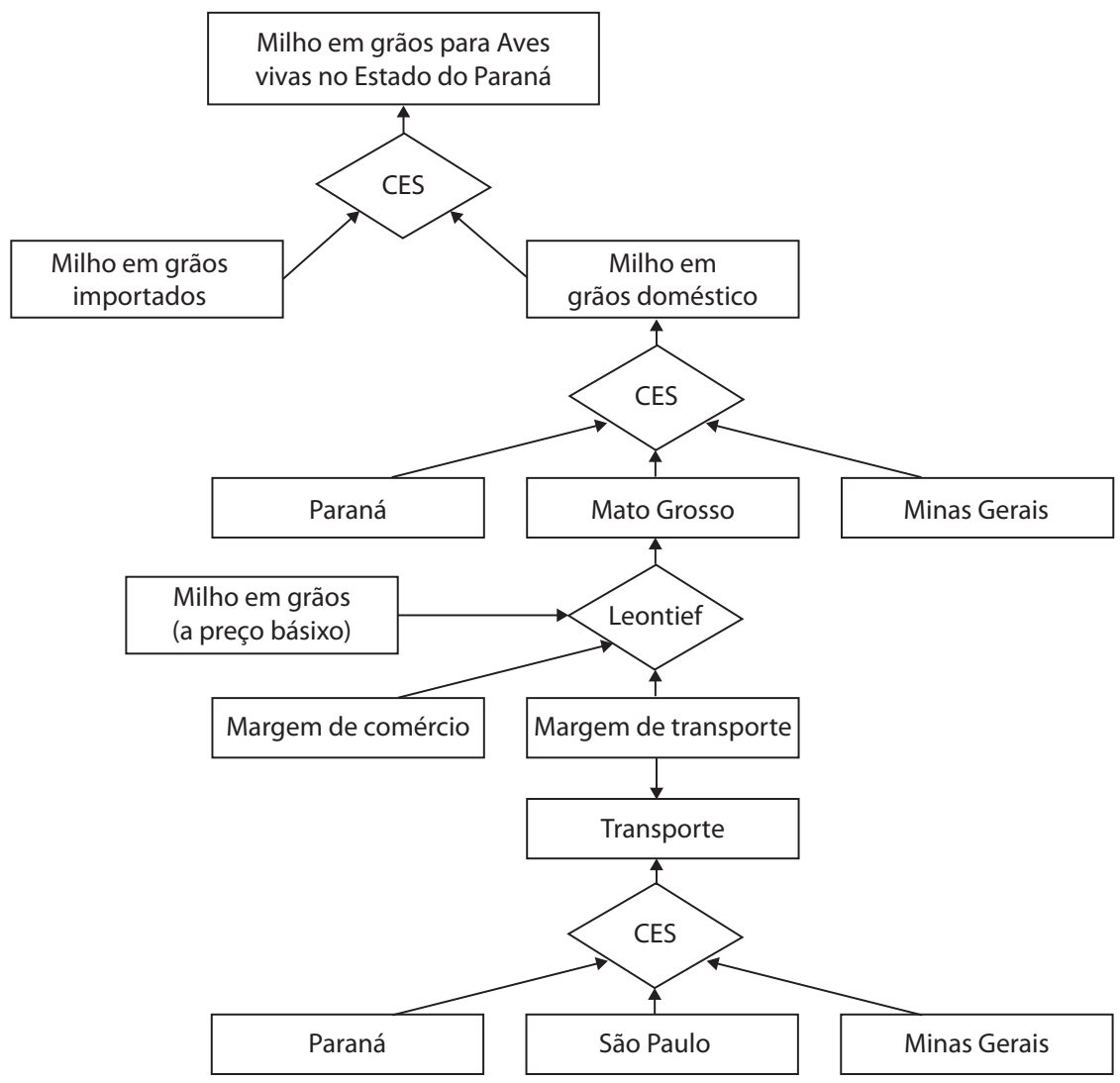

Fonte: Adaptado de Horridge, Madden e Wittwer (2005, p. 292).

O próximo nível mostra como a entrega de milho em grãos, de Mato Grosso, por exemplo, é uma composição Leontief entre o milho em grãos a preço básico e os bens margens (comércio e transportes utilizados na comercialização). A parcela de cada margem no preço de entrega é específica para uma combinação particular de origens, destinos, commodities e fonte. Por exemplo, espera-se que 
o custo de transporte seja mais elevado de maneira a compor parte das ligações comerciais entre regiões distantes, ou para bens pesados ou volumosos.

Por último, a Figura 1 mostra o mecanismo de origem da margem transporte. Nota-se que as margens podem ser produzidas em diferentes regiões. A taxa de substituição entre as regiões produtoras de margens corresponde a 1,0 neste modelo. Neste caso, a participação de uma região produtora de margens para um destino deve ser a mesma para todos os produtos.

Quando a opção do usuário é sobre produtos importados, no primeiro nível apresentado, apesar de não aparecer na Figura 1, um sistema paralelo de origens é modelado localizando o porto de entrada ao invés da região de produção. Dessa forma, finaliza-se toda a estrutura de origem dos produtos demandados pelos diversos usuários do sistema.

Resta apenas analisar a estrutura de produção do modelo TERM-BR (Figura 2), criada com a intenção de otimizar diversos níveis do processo produtivo. A escolha do bem a ser produzido ocorre por meio de uma função de elasticidade constante de transformação (CET), cujo sinal é oposto a CES, pois induz à transformação em favor do bem que tiver seu preço relativo aumentado. Ainda na produção é utilizada uma função Leontief (proporções fixas) para combinar as quantidades necessárias de bens intermediários, fatores primários e outros custos, como os impostos sobre a produção. As demais escolhas a serem realizadas pelas firmas ocorrem por meio de uma função CES.

No topo da Figura 2, usando uma função CET, por meio de uma elasticidade de transformação, a firma é capaz de optar pela produção do bem cujo preço relativo está aumentando, tornando possível alterar a composição da produção da firma.

Após escolher o bem a ser produzido pela firma, ela utiliza uma função Leontief para determinar a quantidade de cada insumo composto, os fatores primários compostos e outros custos que serão gastos na produção do bem escolhido.

Ao escolher os insumos, a firma pode optar por aqueles de origem importada ou doméstica. Apesar de as mercadorias importadas terem uma única origem (o resto do mundo), quando chegam aos portos brasileiros elas sofrem o mesmo processo que os bens domésticos, isto é, a região de origem passa a ser o estado onde está localizado o porto que recebeu as mercadorias. Dessa forma, a elasticidade de Armington intermedeia a escolha entre a parte de bens domésticos e importados. Depois, o estado de origem desses bens é escolhido pela elasticidade de substituição entre origens domésticas que é responsável por determinar a origem regional do insumo. No caso de produtos importados, isso significa que ele foi importado por um porto localizado na região de origem, apesar de não aparecer na Figura 2. Nesse sentido, a elasticidade de substituição entre origens atua de forma similar tanto para bens domésticos como para importados. 


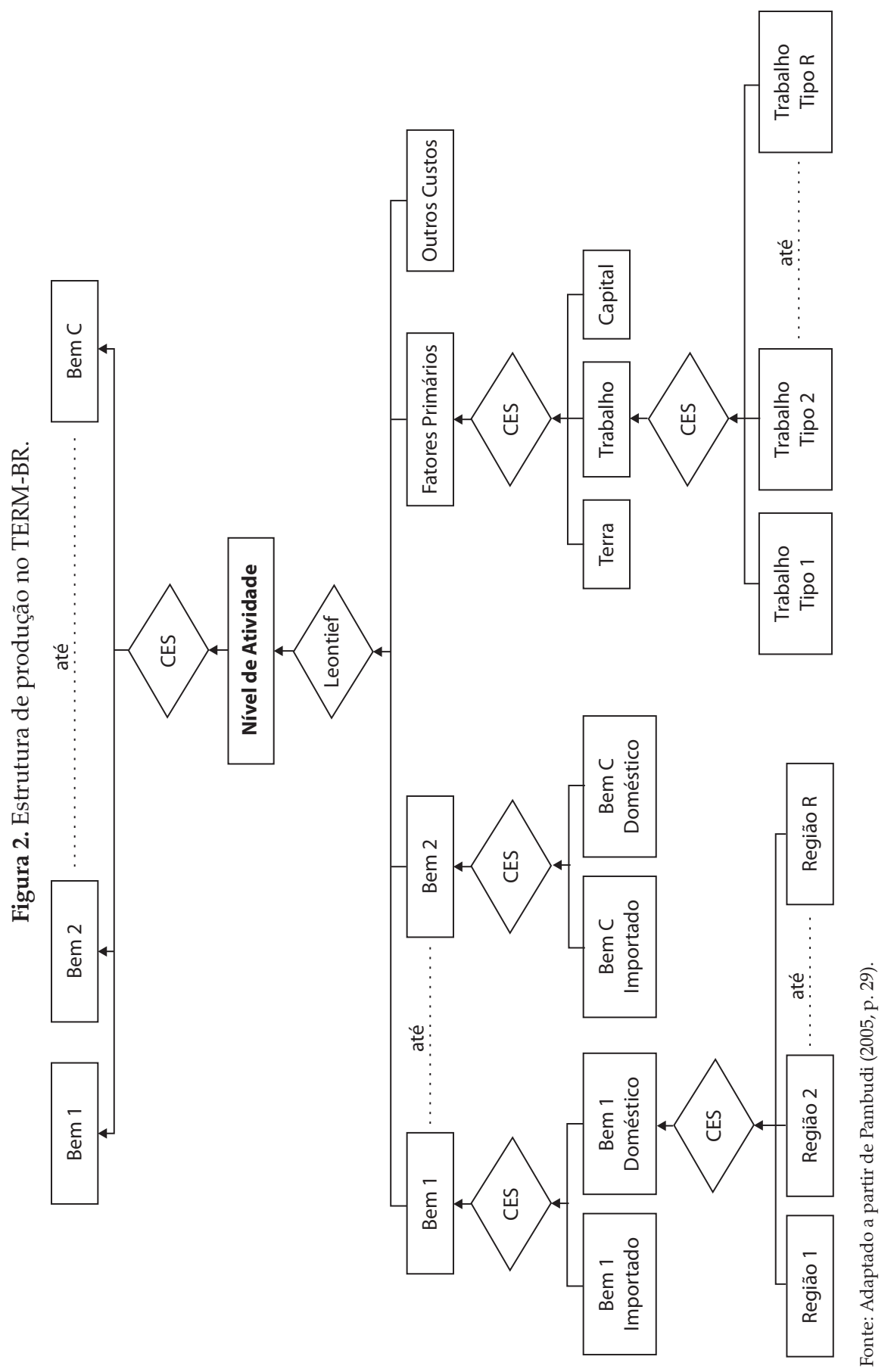

RESR, Piracicaba, SP, vol. 49, no 01, p. 81-108, jan/mar 2011 - Impressa em maio 2011 
Uma função CES também é utilizada para definir a proporção de fatores primários. Neste caso, a elasticidade de substituição entre os fatores primários é responsável pelas escolhas entre terra, capital e trabalho.

Na elaboração do banco de dados do modelo TERM-BR utiliza-se a matriz insumo-produto brasileira de $2001^{4}$. Apesar de diversas mudanças terem ocorrido no setor de milho desde 2001, tais como o aumento da produção na região Centro-Oeste e das exportações brasileiras, a base de dados de 2001 é a mais atual disponível com o maior conjunto de informações para um estudo dessa natureza.

A calibração, procedimento que envolve a escolha dos valores dos parâmetros, não pode ser deduzida das informações das matrizes, como as elasticidades. Para a elasticidade de Armington foram utilizadas as 28 elasticidades estimadas por Tourinho, Kume e Pedroso (2003) para o Brasil, assim como estimativas disponíveis na base de dados do Gtap (DIMARANAN, 2006), visto que estas não existem para esses setores no País. Para a elasticidade de substituição entre origens domésticas, foi utilizado o valor de 1 para todos os produtos. Para a elasticidade de substituição entre origens de margens foi utilizado o valor de 1 (Cobb-Douglas), para margens de comércio e transporte. Tanto para a elasticidade de transformação como para a elasticidade de substituição entre fatores primários foi utilizado o valor de 0,5 para todos os setores e fatores, estimativa padrão adotada nos modelos australianos por ausência de estimativas específicas. A elasticidade de substituição entre tipo de ocupação não é utilizada para o estudo, pois como mencionado, há somente um tipo de trabalho representativo. As elasticidades de demanda por exportações foram extraídas da base de dados do Gtap. Para as elasticidades de dispêndio das famílias, utilizaram-se os 11 parâmetros estimados em Hoffmann (2000), e nos demais produtos, as elasticidades disponíveis na base de dados do Gtap. O parâmetro de FRISCH adotado foi de -2,3235. Já os dados de população em cada unidade da Federação em 2001 foram obtidos das Contas Regionais do Brasil (IBGE, 2004).

O modelo é implementado para as 27 regiões do País (26 estados e o Distrito Federal). Porém, em razão da enorme quantidade de dados gerados, os resultados serão apresentados de forma agregada para as cinco macrorregiões: Norte (N), Nordeste (NE), Centro-Oeste (CO), Sudeste (SE) e o Sul (S). Ao longo do texto, quando relevante, são mencionados alguns estados.

Quanto às atividades produtivas do modelo, a agregação realizada na base de dados permite observar, separadamente, 31 atividades econômicas e 37 produtos. Porém, serão analisados no texto apenas os setores que utilizam o

4 A matriz de 2001 publicada pelo IBGE (www.ibge.gov.br) está a preços de consumidores. A matriz aqui utilizada foi transformada para preços básicos, e geradas as matrizes intermediárias de passagem, por Ferreira Filho (2006). 
milho como insumo, doravante denominados setores a jusante (milho em grãos, suínos, aves vivas, abate de aves, abate de outros animais, outras indústrias de alimentos, leite natural, beneficiamento vegetal, bovinos e fabricação de calçados), setores fornecedores de insumos para a produção de milho, doravante denominados setores a montante (químicos diversos, refino de petróleo, óleo combustível) e setores que competem por fatores produtivos (soja em grão, fabricação de óleo ${ }^{5}$, outros produtos agropecuários).

\subsection{Fechamento do modelo}

Apesar de os modelos de equilíbrio geral serem microeconômicos, fundamentados pela teoria Walrasiana ${ }^{6}$, o seu nível de consistência interna faz com que haja necessidade de equilíbrio entre os fluxos agregados da economia. A forma como ocorre o equilíbrio macroeconômico depende das diferentes correntes teóricas e é determinado pelos fechamentos dos modelos de equilíbrio geral.

O fechamento também está associado com o horizonte temporal simulado, podendo ser de curto ou longo prazo. De forma geral, os salários reais e o estoque de capital são considerados fixos no curto prazo, enquanto no longo prazo ambos são endógenos, sendo que o estoque de capital tende a se mover para os setores e regiões mais atrativas, refletindo a capacidade de investimento na economia ao longo do tempo.

Neste trabalho, opta-se pelo fechamento de longo prazo, uma vez que é possível visualizar melhor as consequências da inovação tecnológica, pois todos os impactos diretos e indiretos já se manifestaram e se esgotaram. Além disso, a taxa de adoção estipulada nessa pesquisa só deverá ser observada no longo prazo, quando a tecnologia estiver bastante disseminada. Este processo ocorrerá de forma gradual, conforme a capacidade de oferta de sementes GM e da confiança do produtor na nova tecnologia.

As principais hipóteses de fechamento consideradas neste modelo foram:

- Os estoques de capital e o investimento em cada indústria e região foram determinados endogenamente, deslocando-se para as regiões mais atrativas. Com isso, as taxas de retorno acabam convergindo aos seus valores iniciais, ou seja, no longo prazo, são fixas.

- A população e a oferta de trabalho agregada são exógenas ao modelo, enquanto o salário real é endógeno. A variação no salário real faz com

5 Apesar de o setor de fabricação de óleo não competir por terra com o setor de milho, ele é composto em grande parte por soja, sofrendo diretamente com a variação nesse setor.

6 A Lei de Walras estabelece que, se em uma economia com $n+1$ mercados, $n$ estiverem em equilíbrio, então o $n+1$ ésimo também estará. 
90 - Impactos Econômicos da Introdução do Milho Bt11 no Brasil:

uma abordagem de equilíbrio geral inter-regional

que a oferta de trabalho (endógena) se desloque entre diferentes setores e regiões.

- Para simplificar, o consumo do governo é exógeno, visto não ser o foco do trabalho. O consumo real das famílias é endógeno, e se ajusta com o investimento para manter a razão entre Balança Comercial e PIB exógena. Esta é uma visão consistente com o fato de que eventuais déficits comerciais não podem ser financiados indefinidamente pelo exterior (SANTOS, 2006).

- Por fim, o numéraire será o IPC (Índice de Preços ao Consumidor) agregado, de forma a facilitar as interpretações dos resultados, uma vez que todos os preços serão expressos em função do IPC.

\subsection{Obtenção de dados}

Neste trabalho são analisados apenas os impactos econômicos da introdução do milho Bt11, devido à indisponibilidade de dados. No entanto, a característica que torna o milho resistente a insetos é a mais comum nas lavouras de milho GM. Dos 21,2 milhões de hectares plantados com milho GM no mundo em 2006, 11,3 milhões de hectares (53,3\%) eram constituídos por milho resistente a insetos (Bt), 6,5 milhões (30,7\%), por milho Bt e tolerante a herbicidas (HT) e 3,4 $(16 \%)$, por milho HT (JAMES, 2007).

Para realizar o choque proposto neste trabalho é necessário estimar o percentual de área plantada com milho que irá adotar sementes GM no longo prazo, em cada estado. Como as características do solo e as pragas existentes em cada região são diferentes, é necessário estimar, por estado, qual será a redução nos custos com combustível, óleo lubrificante, pesticidas, fungicidas, herbicidas, corretivos para o solo e mão de obra, bem como o aumento na produtividade. Neste item, será descrito detalhadamente o processo de obtenção de dados.

Inicialmente, deve-se projetar qual será a taxa de adoção da tecnologia em cada região. Aqui, admite-se a hipótese de que, quanto mais elevada a produtividade de uma região, maiores são os gastos com novas tecnologias e defensivos, e maior a possibilidade de adotar sementes GM. Analisando-se a difusão da produção de milho GM em outros países, acredita-se que a taxa de adoção de milho GM no Brasil deverá oscilar entre a adoção do Uruguai e dos EUA, assemelhando-se à taxa de adoção da Argentina e da África do Sul, ou seja, entre $50 \%$ e $70 \%$ no longo prazo.

Para obter a área "tecnificada" em cada estado, que por hipótese adotará milho Bt11, utiliza-se a produtividade média de cada município em 2006 e 2007 (IBGE, 2008). Se o município possui produtividade acima da média nacional, considera-se que, no longo prazo, toda sua área plantada com milho adotará sementes GM. Ao somar a área plantada dos municípios com produtividade acima da média nacional tem-se a área total no estado que, no modelo, irá adotar 
o milho $\mathrm{GM}^{7}$. Ao dividir essa área pela área plantada total, tem-se o percentual de adoção (Tabela 1).

A taxa de adoção do milho GM para cada estado é de suma importância para mensurar os impactos decorrentes da utilização dessa tecnologia. Como no modelo existe um único produtor (representativo) de milho, as variações observadas nas reduções de custo com insumos e mão de obra, bem como na produtividade, serão introduzidas no modelo ponderado pela taxa de adoção (Tabela 1).

Para obter os dados referentes às reduções de custos das lavouras com milho Bt11 em relação ao cereal convencional, por região, utilizam-se os dados apresentados no trabalho de Ferreira Filho et al. (2008). Neste trabalho, foram realizados 18 levantamentos de custos que contêm safra e safrinha, em 16 municípios, de nove estados brasileiros. Para as finalidades deste trabalho, admite-se que os estados do Pará, Tocantins, Maranhão, Piauí, Espírito Santo e Rio de Janeiro (onde não havia planilhas de custo) utilizam as alterações no custo de produção levantadas no município de Barreiras, na Bahia. Este procedimento se justifica mediante as observações feitas nessas regiões, uma vez que em todos esses estados existem pequenas áreas com produtividade elevada, mesmo com baixa produtividade média.

Nos estados onde mais de um levantamento foi realizado, as alterações nos custos de produção foram ponderadas pelas mesorregiões com produtividades similares, levando-se em consideração, na região, o predomínio de safra ou safrinha. Por fim, nos estados de São Paulo, Santa Catarina e Goiás, são utilizados os levantamentos de custos realizados nos municípios de Assis, Campos Novos e Rio Verde, respectivamente.

Também será necessário organizar os dados originais da pesquisa de Ferreira Filho et al. (2008) para obter setores compatíveis com a agregação do modelo. Os produtos químicos utilizados no modelo estão incluídos no agregado denominado de OutQuímicos, sendo que o setor de milho corresponde a produtos como pesticidas, fungicidas, herbicidas e corretivos para solo. Para obter a redução no custo proveniente de produtos químicos foram agregados herbicidas, fungicidas, inseticidas, tratamento de sementes e adjuvantes existentes na pesquisa de Ferreira Filho et al. (2008), de forma a corresponder aos mesmos elementos do setor de OutQuímicos.

Outra alteração realizada foi nos tratos culturais. De acordo com os dados primários da pesquisa, observa-se que, ao introduzir o milho Bt11, ocorre uma redução nos custos com tratos culturais, dos quais $80 \%$ correspondem a combustível e $20 \%$, a lubrificantes e afins. Dessa forma, se em determinada região ocorrer $50 \%$ de redução nos custos com tratos culturais, haverá redução de $40 \%$

7 Nos estados com predomínio de milho de segunda safra ("safrinha"), foi utilizada a média nacional da safrinha para fazer a mesma comparação. 
nos custos com combustível, denominado de óleo combustível (OleoCombust) no modelo e $10 \%$ com lubrificantes e afins, denominado de outros refinos de petróleo (OutRefPetrol) no modelo. Para os setores de transporte e comércio não é necessária nenhuma alteração, assim como para a quantidade total de mão de obra.

Como o milho foi definitivamente liberado em 2008, sementes GM produzidas no País ainda não são encontradas no Brasil, e, portanto, não se sabe ao certo quanto será seu preço, devido à inovação tecnológica introduzida. Todavia, informações coletadas no mercado mostram uma tendência das empresas de biotecnologia instaladas no Brasil de cobrarem valor semelhante às reduções nos custos com insumos proporcionados pelas sementes GM. Dessa forma, será utilizada a hipótese de que o aumento no custo com semente será proporcional à redução nos custos com insumos decorrentes dessa inovação tecnológica em cada região.

Portanto, o produtor, ao utilizar lavouras com sementes de milho Bt11, ganha com o aumento na produtividade e com a redução no custo com mão de obra correspondente à região. Apesar de o aumento na produtividade variar por região, uma vez que está relacionado à incidência de pragas, utiliza-se aumento de $10 \%$ para todas as regióes, ponderado pela taxa de adoção, por não haver nenhum trabalho que mostre possíveis diferenciações nas regiões brasileiras, e por ser um valor estimado por James (2003) para as regiões brasileiras que possuem controle químico de pragas.

Não serão analisadas mudanças nas preferências dos consumidores, nem diferenciação no preço do milho convencional e GM. Para haver reação dos consumidores, eles deveriam ser capazes de diferenciar o produto GM do convencional. Em relação a grãos, é possível realizar testes, sem necessidade de rastrear o produto. Porém, para animais alimentados com produtos GM, ou alimentos processados, como óleo de milho, a identificação por meio de testes não é possível, sendo necessário rastrear toda a cadeia produtiva. Isso exigiria intensa fiscalização do governo e dos órgãos responsáveis. Mesmo que todo esse processo fosse possível, não se sabe ao certo quanto os consumidores estão dispostos a pagar a mais por isso, principalmente a indústria de ração e os exportadores. No entanto, determinados países poderiam partir do pressuposto de que todo o milho produzido no Brasil é GM e, assim, proibir as importações brasileiras de milho. Porém, o trabalho de Ferreira Filho (2007) mostra que a maioria dos países importadores tem aceitado bem o milho GM, principalmente aquele destinado à alimentação animal. 
Tabela 1. Taxa de adoção do milho GM e variação nos custos por setor e estado a serem utilizados nas simulações (em \%).

\begin{tabular}{|c|c|c|c|c|c|c|c|c|}
\hline & $\begin{array}{l}0 \\
\text { d } \\
\frac{\pi}{2}\end{array}$ & 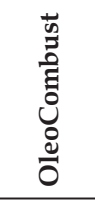 & 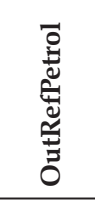 & 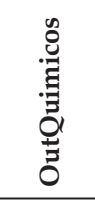 & 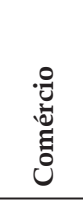 & 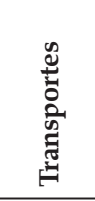 & 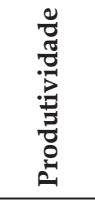 & 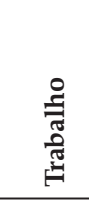 \\
\hline Pará & 16,80 & $-6,48$ & $-1,62$ & $-6,10$ & 1,68 & 0,00 & 1,68 & $-1,01$ \\
\hline Tocantins & 3,95 & $-1,52$ & $-0,38$ & $-1,43$ & 0,39 & 0,00 & 0,39 & $-0,24$ \\
\hline Maranhão & 3,29 & $-1,27$ & $-0,32$ & $-1,20$ & 0,33 & 0,00 & 0,33 & $-0,20$ \\
\hline Piauí & 3,93 & $-1,52$ & $-0,38$ & $-1,43$ & 0,39 & 0,00 & 0,39 & $-0,24$ \\
\hline Bahia & 18,07 & $-6,97$ & $-1,74$ & $-6,56$ & 1,81 & 0,00 & 1,81 & $-1,09$ \\
\hline Minas & 71,38 & $-16,35$ & $-4,09$ & $-21,03$ & 7,14 & 7,14 & 7,14 & $-11,72$ \\
\hline Espírito Santo & 7,60 & $-2,93$ & $-0,73$ & $-2,76$ & 0,76 & 0,00 & 0,76 & $-0,46$ \\
\hline Rio de Janeiro & 3,88 & $-1,50$ & $-0,37$ & $-1,41$ & 0,39 & 0,00 & 0,39 & $-0,23$ \\
\hline São Paulo & 66,18 & $-26,47$ & $-6,62$ & $-10,12$ & 6,62 & 6,62 & 6,62 & $-12,15$ \\
\hline Paraná & 85,70 & $-37,04$ & $-9,26$ & $-22,97$ & 0,00 & 8,57 & 8,57 & $-15,83$ \\
\hline Santa Catarina & 80,86 & $-18,40$ & $-4,60$ & $-13,98$ & 0,00 & 8,09 & 8,09 & $-3,74$ \\
\hline Rio G. do Sul & 51,91 & 0,00 & 0,00 & $-7,47$ & 1,25 & 5,19 & 5,19 & 0,00 \\
\hline Mato G. do Sul & 65,80 & $-17,69$ & $-4,42$ & $-17,61$ & 6,58 & 5,97 & 6,58 & $-12,01$ \\
\hline Mato Grosso & 87,45 & $-51,82$ & $-12,95$ & $-30,63$ & 8,67 & 8,67 & 8,67 & $-7,03$ \\
\hline Goiás & 88,09 & $-20,85$ & $-5,21$ & $-19,88$ & 8,81 & 8,81 & 8,81 & $-6,85$ \\
\hline Distrito Federal & 100,00 & $-23,67$ & $-5,92$ & $-22,57$ & 10,00 & 10,00 & 10,00 & $-7,78$ \\
\hline
\end{tabular}

Nota: Simulação das alterações nos custos provenientes da redução de $100 \%$ no uso de inseticidas e $10 \%$ de aumento na produtividade.

Fonte: Elaborado com base em Ferreira Filho et al. (2008).

De posse desses dados, dois cenários serão simulados:

- Cenário I: todas as áreas plantadas com milho no Brasil que possuem produtividade acima da média nacional irão adotar milho Bt11, conforme apresentado na Tabela 1;

- Cenário II: o Paraná não adota milho Bt11, visto que, em 2003, este estado decretou a lei $n^{0}$ 14.162, que veda o cultivo, manipulação, industrialização e comercialização de organismos $\mathrm{GM}^{8}$.

As análises desses cenários poderão ser úteis para compreender o processo que ocorre quando uma região se abstém da adoção de produtos GM,

8 A lei estadual no 14.162/03 do Paraná foi declarada inconstitucional pelo Supremo Tribunal Federal (STF) por estar contra a norma federal no 8.974/95. Mais informações podem ser encontradas no informativo de Flavia Scarpinella Bueno, disponível em: www.correiadasilva.com.br/pdf/info_amb/infoamb11.pdf. 
Impactos Econômicos da Introdução do Milho Bt11 no Brasil:

uma abordagem de equilíbrio geral inter-regional

enquanto as regiões próximas usufruem dos benefícios da adoção, e o produtor convencional não obtém nenhuma vantagem adicional, como diferenciação no preço. Esse cenário é parecido com o que vem ocorrendo no Brasil desde a adoção de milho GM na Argentina, por exemplo.

\section{Resultados e Discussão}

\subsection{Cenário I: adoção de milho GM no Brasil}

No cenário I, uma taxa de adoção de aproximadamente $60 \%$ da área plantada com milho no Brasil em 2001 é simulada. A distribuição da produção e o percentual adotado em cada região podem ser visualizados na Tabela 2, junto ao resultado agregado. Neste cenário, observa-se aumento do PIB brasileiro, sendo maior para os estados que adotaram milho Bt11 e para as regiões mais economicamente dependentes dos setores a jusante da cadeia produtiva do milho.

A adoção do milho Bt11 reduz o preço do cereal e dos produtos que o utilizam ao longo do processo produtivo, o que contribui para o crescimento das exportações desses produtos. Por outro lado, com menor intensidade, o aumento no salário real médio aumento o consumo de produtos nacionais e importados. Como a variação no saldo da balança comercial é mantida fixa em relação ao PIB no fechamento, ocorre, inicialmente, um superávit na balança comercial, sendo necessário apreciar a moeda doméstica corrente (redução da taxa de câmbio), elevando as importações e dificultando as exportações.

A variação no emprego agregado (nacional) é nula, devido ao fechamento realizado, sendo a redução na quantidade da mão de obra no setor de milho compensado pelo aumento no nível de atividade de setores a jusante da sua cadeia produtiva, ou realocada para a região Sul, onde o aumento no nível de atividade foi maior (Tabela 2).

Como o choque simula a adoção de uma tecnologia que poupa mão de obra, é possível existir redução nos postos de trabalho em algumas regiões mesmo com aumento do PIB, como ocorre, por exemplo, no Centro-Oeste. Entretanto, cabe ressaltar que o aumento no salário real médio ocorre em todas as regiões, uma vez que o crescimento no salário real em algumas regiões atrai mão de obra de outras regiões, onde há retração no nível de atividade.

As variações macroeconômicas decorrentes da introdução do milho Bt11 não ocupam grandes destaques, visto que a participação dos setores inter-relacionados na cadeia de comercialização do milho é pequena em relação aos demais setores analisados, representando cerca de 8,5\% do PIB nacional em 2001. Porém, cabe analisar criteriosamente os impactos da adoção de milho Bt11 nos diversos setores ligados direta e indiretamente com o produto e quais os efeitos sobre as regiões brasileiras. 
Com a introdução do milho Bt11 no Brasil, ocorre uma redução de 9,37\% nos custos totais do setor de milho, já considerando o aumento no preço da semente GM em relação ao da convencional. As variações nos custos de produção de cada setor acompanham a variação do preço do milho de sua região que, por sua vez, depende da taxa de adoção de milho Bt11 e da demanda pelo cereal na região.

Tabela 2. Cenário I: efeitos de longo prazo sobre os principais agregados macroeconômicos - Brasil e grandes regiões - (em \%).

\begin{tabular}{lccccccc}
\hline & Brasil & Norte & Nordeste & $\begin{array}{c}\text { Centro- } \\
\text {-Oeste }\end{array}$ & Sudeste & Sul & Paraná \\
\hline Hipóteses do modelo & & & & & & & \\
$\quad$ Valor total produzido em 2001 (\%) & 100,00 & 3,11 & 5,91 & 16,09 & 21,31 & 53,58 & 27,53 \\
$\quad$ Adoção (\%) & 60,36 & 10,32 & 6,08 & 82,12 & 67,29 & 74,40 & 85,70 \\
\hline Resultados obtidos & & & & & & & \\
$\quad$ Indicadores Agregados & & & & & & & \\
$\quad$ PIB real & 0,06 & $-0,05$ & $-0,01$ & 0,14 & 0,01 & 0,28 & 0,62 \\
$\quad$ Taxa de câmbio & $-0,04$ & $X$ & $X$ & $X$ & $X$ & $X$ & $X$ \\
Demanda Agregada & & & & & & & \\
$\quad$ Consumo real das famílias & 0,10 & $-0,01$ & 0,08 & 0,04 & 0,09 & 0,21 & 0,47 \\
$\quad$ Estoque de capital & $-0,02$ & $-0,13$ & $-0,05$ & $-0,02$ & $-0,04$ & 0,08 & 0,28 \\
$\quad$ Volume de exportação & 0,04 & $-0,23$ & $-0,31$ & $-0,40$ & $-0,30$ & 0,77 & 2,38 \\
$\quad$ Volume de importação & 0,04 & $-0,03$ & 0,09 & 0,04 & 0,04 & 0,07 & 0,24 \\
Mercado de trabalho & & & & & & & \\
$\quad$ Emprego & - & $-0,06$ & $-0,01$ & $-0,03$ & $-0,01$ & 0,05 & 0,18 \\
$\quad$ Salário real médio & 0,08 & 0,03 & 0,08 & 0,05 & 0,08 & 0,13 & 0,26 \\
$\quad \begin{array}{l}\text { Preços } \\
\text { Índice de preços ao consumidor }\end{array}$ & - & $-0,03$ & 0,01 & $-0,01$ & 0,00 & 0,01 & 0,07 \\
\hline
\end{tabular}

Fonte: Dados da pesquisa.

A redução no preço do milho eleva a demanda pelo produto e incentiva o aumento do nível de atividade do setor. Este, por sua vez, demanda mais insumos, forçando a alta nos preços desses produtos.

As alterações no custo total de produção nos setores selecionados estão na Tabela 3. Nos setores que utilizam o milho como insumo, como aves e suínos, o custo tende a cair, e essa redução é proporcional à quantidade percentual de milho utilizada em cada setor. Nos demais setores, a jusante da cadeia produtiva do milho, como os de abate animal, a redução tende a ser bem menor que nos setores que consomem o milho diretamente. 
96 - Impactos Econômicos da Introdução do Milho Bt11 no Brasil:

uma abordagem de equilíbrio geral inter-regional

Para os demais setores que não utilizam milho direta ou indiretamente, ou que utilizam uma proporção muito pequena, o custo de produção tende a subir devido à elevação nos preços dos fatores de produção.

Tabela 3. Cenário I: variação nos índices de custo total, devido à introdução de milho $\mathrm{GM}$ - grandes regiões - (em \%).

\begin{tabular}{lccccccc}
\hline \multicolumn{1}{c}{ Setor de atividade } & Brasil & Norte & Nordeste & $\begin{array}{c}\text { Centro- } \\
\text {-Oeste }\end{array}$ & Sudeste & Sul & Paraná \\
\hline Soja em grão & 0,00 & $-0,01$ & $-0,01$ & 0,00 & 0,01 & 0,00 & 0,02 \\
Milho em grão & $-9,37$ & $-3,47$ & $-2,88$ & $-11,27$ & $-11,35$ & $-9,07$ & $-10,96$ \\
Bovinos & 0,01 & 0,00 & 0,01 & $-0,01$ & 0,00 & 0,05 & 0,07 \\
Suínos & $-1,74$ & $-1,29$ & $-1,23$ & $-1,91$ & $-2,00$ & $-1,69$ & $-1,85$ \\
Leite natural & $-0,08$ & $-0,05$ & 0,00 & $-0,13$ & $-0,12$ & 0,00 & 0,09 \\
Aves vivas & $-1,42$ & $-0,94$ & $-1,01$ & $-1,69$ & $-1,72$ & $-1,29$ & $-1,47$ \\
Outros produtos agropecuários & 0,05 & 0,02 & 0,04 & 0,04 & 0,06 & 0,06 & 0,18 \\
Refino de petróleo & 0,04 & 0,03 & 0,03 & 0,02 & 0,04 & 0,05 & 0,10 \\
Químicos diversos e fármacos & 0,03 & 0,01 & 0,04 & 0,02 & 0,03 & 0,05 & 0,11 \\
Abate de aves & $-0,83$ & $-0,48$ & $-0,52$ & $-0,99$ & $-0,97$ & $-0,77$ & $-0,84$ \\
Abate de outros animais & $-0,26$ & $-0,25$ & $-0,23$ & $-0,28$ & $-0,28$ & $-0,22$ & $-0,21$ \\
Outras indústrias de alimentos & $-0,17$ & $-0,15$ & $-0,04$ & $-0,23$ & $-0,19$ & $-0,17$ & $-0,11$ \\
Fabricação de óleo vegetal & 0,02 & 0,01 & 0,02 & 0,01 & 0,01 & 0,03 & 0,08 \\
\hline
\end{tabular}

Fonte: Dados da pesquisa.

Com a redução no custo de produção de alguns setores, as famílias poderão adquirir produtos como leite natural e carnes a um preço menor. Os produtos que tiveram aumento de preço para as famílias foram outros produtos agropecuários, como de couro e calçados e óleo vegetal, que é constituído, basicamente de óleo de soja. As famílias do Centro-Oeste foram as mais beneficiadas, pois a redução expressiva no valor do milho foi repassada para os preços de diversos produtos adquiridos pelas famílias.

Em decorrência da redução do preço, as famílias aumentarão o consumo. Embora as maiores taxas de diminuição de cotações tenham ocorrido no Centro-Oeste, os resultados do modelo mostram variação maior no consumo das famílias da região Sul do País, em função do aumento na quantidade de postos de trabalho (emprego) e no salário real médio (Tabela 4).

A redução no consumo das famílias da região Norte é relativamente pequena, pois o setor de milho, bem como os demais setores a jusante da sua cadeia produtiva, tem pequena participação na composição do seu PIB.

Em todos os estados, verifica-se aumento nas exportações de milho. No entanto, 99\% delas são da região Sul, observando-se, no Paraná, a maior variação 
nos embarques $(44,6 \%)$. Os produtos com as maiores quedas de preços tiveram os maiores aumentos na quantidade exportada. No setor de carne de aves, o aumento nos envios foi de $3 \%$.

Tabela 4. Cenário I: variação no consumo das famílias devido à introdução de milho $\mathrm{GM}$ - grandes regiões - (em \%).

\begin{tabular}{lccccccc}
\hline \multicolumn{1}{c}{ Produto } & Brasil & Norte & Nordeste & $\begin{array}{c}\text { Centro- } \\
\text {-Oeste }\end{array}$ & Sudeste & Sul & Paraná \\
\hline Leite natural & 0,04 & 0,00 & 0,05 & 0,03 & 0,05 & 0,10 & 0,21 \\
Outros produtos agropecuários & 0,03 & $-0,01$ & 0,04 & 0,00 & 0,02 & 0,11 & 0,25 \\
Produtos de couro e calçados & 0,07 & $-0,03$ & 0,09 & 0,03 & 0,07 & 0,28 & 0,58 \\
Beneficiamento vegetal & 0,02 & 0,00 & 0,03 & 0,02 & 0,03 & 0,07 & 0,14 \\
Carne bovina & 0,08 & 0,04 & 0,10 & 0,06 & 0,09 & 0,17 & 0,33 \\
Carne suína & 0,10 & 0,04 & 0,11 & 0,08 & 0,10 & 0,19 & 0,35 \\
Carne de aves abatidas & 0,06 & 0,05 & 0,06 & 0,06 & 0,06 & 0,08 & 0,13 \\
Óleo vegetal refinados & 0,01 & $-0,01$ & 0,01 & 0,00 & 0,01 & 0,06 & 0,12 \\
Outros alimentos e bebidas & 0,05 & 0,02 & 0,06 & 0,04 & 0,06 & 0,13 & 0,23 \\
\hline
\end{tabular}

Fonte: Dados da pesquisa.

Por outro lado, em setores que apresentam aumento no custo de produção, como o setor de soja, ocorre redução nas exportações, devido à elevação no preço e à valorização cambial. Com isso, produtos derivados também incorreram em redução nas exportações como, por exemplo, o óleo vegetal.

Com o aumento na demanda por milho, ocorre um crescimento do nível de atividade de setores inter-relacionados na sua cadeia de comercialização, inclusive do próprio setor de milho, cujo aumento no nível de atividade no Brasil atinge 7,69\%. Essa elevação é impulsionada pelos estados com alta taxa de adoção de milho Bt11, ou seja, todos os estados do Sul e do Centro-Oeste, além de São Paulo e Minas Gerais, no Sudeste.

Entre esses estados, o Paraná é o que apresenta o maior crescimento no nível de atividade $(21,24 \%)$. Contudo, esse aumento não ocorre apenas devido à elevada taxa de adoção, mas também em função de a demanda por milho na região ser maior em relação à verificada em outros locais. Dessa forma, uma redução relativamente menor no preço do milho é capaz de aumentar a demanda pelo produto, se comparado com outras regiões. No Paraná, também é observada maior elevação no nível de atividade no setor de aves. Entretanto, o maior aumento no nível de atividade no setor de suínos ocorre na região Centro-Oeste, apesar de a maior variação absoluta também ocorrer na região Sul, visto que concentrava 73\% do valor produzido pelo setor de suínos em 2001.

Os setores que apresentam aumento no nível de atividade demandam mais mão de obra, compensando o desemprego gerado pela introdução do milho 
Bt11. Nos estados onde se observa redução no nível de atividade, a redução na demanda por mão de obra faz com que ela se desloque para os estados onde ocorre o movimento inverso. Como o nível de atividade nos setores a jusante da cadeia produtiva do milho no Paraná e em Santa Catarina cresceu muito em relação aos demais estados, esses acabam atraindo mão de obra. Por outro lado, os estados do Centro-Oeste, Rio Grande do Sul, Minas Gerais, Espírito Santo e Bahia reduzem os postos de emprego, uma vez que o desemprego causado pela inovação tecnológica não é suprido pela demanda por mão de obra em outros setores.

Na região Sul, apesar de a introdução do milho Bt11 gerar desemprego, a redução no preço eleva a demanda pelo produto, incentivando a produção. Com isso, o setor acaba aumentando a procura por mão de obra numa quantidade similar ao desemprego gerado pela inovação tecnológica. Mas, como a redução no preço do milho incentiva o aumento na produção de outros setores, a região absorve mais mão de obra do que a desempregada no começo do processo. No Paraná, por exemplo, apenas o aumento na produção de milho mais que compensa o desemprego causado pela introdução do milho Bt11.

Para efeito de comparação, os resultados encontrados por Fancelli (2002), bem como os obtidos neste trabalho, estimam ganhos consideráveis com a introdução do milho resistente a insetos. Fancelli (2002) estima que os benefícios diretos e indiretos da introdução de milho resistente a insetos seriam de cerca de US\$ 1,2 bilhão, enquanto que o ganho de bem-estar obtido neste trabalho corresponde a $\mathrm{R} \$ 701,76$ milhões 9 .Como visto, portanto, a introdução do milho Bt11 terá efeito positivo em longo prazo, não apenas no setor de milho, como também nos setores inter-relacionados na sua cadeia de comercialização. A redução no custo desses setores atinge as famílias, que poderão adquirir os produtos a custos mais baixos, aumentando o consumo, principalmente de carnes. Por outro lado, o aumento da demanda, tanto interna quanto externa, incentiva o aumento da oferta e, como consequência, do emprego nas regiões em que os setores afetados exercem maior participação no PIB, como, por exemplo, na região Centro-Oeste e, sobretudo, no Sul do País.

Considerando-se, portanto, que a introdução de lavouras de milho Bt11 no Brasil não proporcionará mudanças nas relações comerciais internacionais, o presente trabalho apresenta resultados similares ao dos trabalhos de Elbehri e Macdonald (2004), Hareau (2006), Gruère, Bouët e Mevel (2007), que também utilizaram modelos de equilíbrio geral para analisar os impactos da adoção de

9 O ganho de bem-estar neste trabalho é medido pela variação equivalente (EV), obtida da função de utilidade indireta e pode ser encontrado no trabalho de Robichaud (2001). Em geral, o ganho de bem-estar em uma região costuma ser bem inferior em modelos de equilíbrio geral, uma vez que são descontadas as perdas nos setores que não estão diretamente envolvidos com o setor analisado. 
lavouras GM. Apesar de estes trabalhos terem como foco a análise de outras culturas GM, os resultados encontrados, de maneira geral, indicam que a introdução de qualquer lavoura GM aumenta a produção, as exportações e o bem-estar da população.

Porém, devido aos pressupostos utilizados no modelo, mesmo com a adoção de milho Bt11 em algumas regiões do Nordeste, o nível de atividade do setor de milho nessa região tem queda. Além disso, no longo prazo, não é esperado aumento na produção, o que contraria as estimativas feitas por Borchgrave $(2002)^{10}$. Isso decorre do fato de que as regiões Sul, Sudeste e Centro-Oeste têm mais acesso a essa inovação tecnológica, obtendo vantagens competitivas em relação ao Nordeste. Em outras palavras, o Nordeste acaba se tornando mais dependente do milho de outras regiões.

\subsection{Cenário II: adoção de milho GM no Brasil, exceto Paraná}

O cenário II, conforme descrito na metodologia, analisa as consequências que a criação de uma lei que proíbe o cultivo de milho GM no Paraná, assim como ocorreu com a soja em 2003, pode gerar para o Brasil, e em especial para o Paraná.

Neste caso, admite-se, na simulação, que o Paraná tem taxa de adoção nula. Com isso, a adoção simulada no Sul do Brasil reduz de 74,7\% no cenário I, para 29,58\% no cenário II. A taxa de adoção no Brasil também tem redução: no cenário I correspondia a $60,36 \%$ da área plantada com milho, enquanto no cenário II, é de 40,79\%.

Na Tabela 5, além das taxas de adoção por região, estão os resultados macroeconômicos do cenário II. A adoção de lavouras de milho Bt11 aumenta o PIB nacional em $0,03 \%$. Esse aumento corresponde à metade da variação percentual observada no cenário I, e reflete-se no consumo das famílias, que, no cenário II aumenta apenas $0,06 \%$, enquanto no cenário I, a elevação é de $0,10 \%$. Essa queda nos índices nacionais ocorre devido à retração sofrida no Sul, principalmente no Paraná, que era responsável por $27,5 \%$ do valor total produzido pelo setor de milho no Brasil em 2001. A região Sul, mesmo sem a adoção do milho Bt11 no Paraná, consegue aumento significativo no PIB em relação às outras regiões $(0,04 \%)$, porém menor que no cenário I $(0,28 \%)$. O Paraná, ao invés do $0,62 \%$ de crescimento no PIB, passa a ter redução de $0,12 \%$ com a não adoção de milho Bt11. Porém, as demais regiões são beneficiadas no cenário II, principalmente o Centro-Oeste e o Sudeste.

10 Borchgrave (2002) calcula aumento de 5\% na produção, admite por hipótese $100 \%$ de adoção e retira do total importado esse aumento na quantidade produzida, mantendo o consumo constante. 
Impactos Econômicos da Introdução do Milho Bt11 no Brasil: uma abordagem de equilíbrio geral inter-regional

A região Centro-Oeste passa a receber capital de todas as regiões. A ampliação do estoque de capital no Centro-Oeste leva ao aumento no nível de atividade, elevando a demanda por mão de obra e o salário real médio, fazendo o PIB da região crescer e a variação no consumo das famílias mais do que dobrar em relação ao cenário I.

A saída de capital na região Sul faz com que a mão de obra, que antes se deslocava de todas as regiões para o Sul, no cenário II, saía do Sul e do Norte para o Centro-Oeste e Sudeste. O Centro-Oeste se torna a região com maior crescimento no nível de atividade, tomando o lugar da região Sul na atração de mão de obra e, portanto, pagando salários mais elevados em relação ao cenário I.

O consumo das famílias continua negativo apenas na região Norte, mesmo com forte retração no consumo das famílias no Paraná $(0,17 \%)$. O volume das exportações continua apresentando elevações apenas nos estados da região Sul, porém, com menor intensidade em relação ao cenário I, pois a redução no preço do milho é inferior. Neste cenário, a redução do preço no setor de milho e setores a jusante não gera aumento na demanda externa suficiente para alterar a taxa de câmbio.

Tabela 5. Cenário II: efeitos de longo prazo sobre os principais agregados macroeconômicos - Brasil e grandes regiões - (em \%).

\begin{tabular}{|c|c|c|c|c|c|c|c|}
\hline & Brasil & Norte & Nordeste & $\begin{array}{l}\text { Centro- } \\
\text {-Oeste }\end{array}$ & Sudeste & Sul & Paraná \\
\hline \multicolumn{8}{|l|}{ Hipóteses do modelo } \\
\hline Valor total produzido em $2001(\%)$ & 100,00 & 3,11 & 5,91 & 16,09 & 21,31 & 53,58 & 27,53 \\
\hline $\operatorname{Adoção~}^{(1)}(\%)$ & 40,79 & 10,32 & 6,08 & 82,12 & 67,29 & 29,58 & 0,00 \\
\hline \multicolumn{8}{|l|}{ Resultados obtidos } \\
\hline \multicolumn{8}{|l|}{ Indicadores Agregados } \\
\hline PIB real & 0,03 & $-0,04$ & 0,00 & 0,19 & 0,03 & 0,04 & $-0,12$ \\
\hline Taxa de câmbio & 0,00 & $x$ & $x$ & $x$ & $x$ & $x$ & $x$ \\
\hline \multicolumn{8}{|l|}{ Demanda Agregada } \\
\hline Consumo real das famílias & 0,06 & $-0,02$ & 0,05 & 0,09 & 0,08 & 0,01 & $-0,17$ \\
\hline Estoque de capital & $-0,02$ & $-0,10$ & $-0,03$ & 0,04 & $-0,02$ & $-0,04$ & $-0,15$ \\
\hline Volume de exportação & 0,01 & $-0,06$ & $-0,13$ & $-0,23$ & $-0,11$ & 0,29 & 0,50 \\
\hline Volume de importação & 0,01 & $-0,04$ & 0,04 & 0,05 & 0,02 & $-0,04$ & $-0,13$ \\
\hline \multicolumn{8}{|l|}{ Mercado de trabalho } \\
\hline Emprego & - & $-0,04$ & 0,00 & 0,01 & 0,01 & $-0,02$ & $-0,12$ \\
\hline Salário real médio & 0,05 & 0,01 & 0,04 & 0,06 & 0,06 & 0,03 & $-0,07$ \\
\hline \multicolumn{8}{|l|}{ Preços } \\
\hline Índice de preços ao consumidor & - & $-0,02$ & 0,01 & 0,01 & 0,00 & $-0,01$ & $-0,03$ \\
\hline
\end{tabular}

Fonte: Dados da pesquisa. 
A variação no custo total de produção (Tabela 6) depende da taxa de adoção de milho Bt11, da demanda do produto na região analisada e da variação no preço dos insumos utilizados. Todavia, a redução do preço em algumas regiões força a queda em todas as regióes do País. Como o Paraná não adota milho Bt11, a diminuição de preço é inferior à observada no cenário I.

No cenário I, a baixa no preço do milho na região Sul era de 9,07\%, enquanto que cenário II, é de apenas 3,71\%. No Paraná, a redução era superior a $10 \%$ ao adotar milho Bt11, contudo, caso não adote, a redução passa a ser quase insignificante $(0,9 \%)$. Nos outros setores a jusante da cadeia produtiva do milho, a análise é similar, porém, com intensidades menores. Enquanto a redução no custo total de produção do milho chega a 11,1\% no Sudeste, o segundo setor com maior variação nos custos de produção é o de suínos, também no Sudeste $(-1,72 \%)$.

A redução percentual nos custos totais de produção do milhoé maior na região Sudeste, pois a demanda na região é pequena, apenas $11 \%$ do valor produzido nacionalmente. $\mathrm{O}$ mesmo tende a ocorrer com produtos intermediários, como suínos e aves vivas, porém, numa proporção menor, visto que a diferença na demanda por esses bens é pequena em relação às outras regiões. Porém, quando o produto é destinado ao consumidor final, como carnes, o consumo na região Sudeste é maior, e a queda nos custos tende a acompanhar os verificados na região Centro-Oeste.

Como os preços na região Sul apresentam pequena tendência à queda, devido à baixa adoção de lavouras de milho Bt11 e à demanda elevada por produtos agropecuários, as famílias dessa região são as menos beneficiadas com a redução nos preços dos produtos, a jusante da cadeia produtiva do milho, reduzindo o consumo, principalmente de carne de aves.

Tabela 6. Cenário II: variação nos índices de custo total, devido à introdução de milho $\mathrm{GM}$ - grandes regiões - (em \%).

\begin{tabular}{lccccccc}
\hline \multicolumn{1}{c}{ Setor de atividade } & Brasil & Norte & Nordeste & $\begin{array}{c}\text { Centro- } \\
\text {-Oeste }\end{array}$ & Sudeste & Sul & Paraná \\
\hline Soja em grão & 0,00 & 0,00 & 0,00 & 0,01 & 0,02 & $-0,01$ & $-0,02$ \\
Milho em grão & $-6,35$ & $-3,21$ & $-2,74$ & $-10,84$ & $-11,07$ & $-3,71$ & $-0,90$ \\
Bovinos & $-0,01$ & $-0,01$ & 0,00 & $-0,01$ & $-0,01$ & 0,00 & 0,00 \\
Suínos & $-1,27$ & $-0,97$ & $-0,96$ & $-1,58$ & $-1,72$ & $-1,15$ & $-0,79$ \\
Leite natural & $-0,08$ & $-0,05$ & $-0,02$ & $-0,10$ & $-0,11$ & $-0,04$ & $-0,08$ \\
Aves vivas & $-1,00$ & $-0,73$ & $-0,81$ & $-1,47$ & $-1,47$ & $-0,77$ & $-0,49$ \\
Outros produtos agropecuários & 0,00 & $-0,02$ & 0,00 & 0,00 & 0,00 & 0,00 & $-0,06$ \\
Refino de petróleo & 0,04 & 0,03 & 0,03 & 0,04 & 0,04 & 0,02 & 0,00 \\
Químicos diversos e fármacos & 0,03 & 0,02 & 0,04 & 0,03 & 0,03 & 0,02 & $-0,02$ \\
Abate de aves & $-0,58$ & $-0,34$ & $-0,39$ & $-0,83$ & $-0,80$ & $-0,48$ & $-0,33$ \\
Abate de outros animais & $-0,19$ & $-0,19$ & $-0,17$ & $-0,21$ & $-0,22$ & $-0,17$ & $-0,14$ \\
Outras indústrias de alimentos & $-0,15$ & $-0,13$ & $-0,05$ & $-0,21$ & $-0,18$ & $-0,12$ & $-0,06$ \\
Fabricação de óleo vegetal & 0,02 & 0,01 & 0,02 & 0,03 & 0,02 & 0,01 & $-0,02$ \\
\hline
\end{tabular}

Fonte: Dados da pesquisa. 
Embora a redução nos valores dos produtos destinados às famílias seja inferior no cenário II, as famílias não só da região Centro-Oeste, mas também da maioria dos estados brasileiros, passam a consumir quantidades maiores de todos os produtos, devido ao aumento na quantidade de emprego e do salário real médio. Vale ressaltar que só houve redução no consumo de carne de aves no Paraná, visto que a queda na quantidade de empregos e no salário real médio reduz o poder de compra das famílias, não sendo observado aumento no consumo nem mesmo de produtos que se desvalorizaram. A variação no consumo das famílias em setores selecionados pode ser visualizada na Tabela 7 .

Tabela 7. Cenário II: variação no consumo das famílias, devido à introdução de milho $\mathrm{GM}$ - grandes regiões - (em \%).

\begin{tabular}{lccccccc}
\hline \multicolumn{1}{c}{ Produtos } & Brasil & Norte & Nordeste & $\begin{array}{c}\text { Centro- } \\
\text {-Oeste }\end{array}$ & Sudeste & Sul & Paraná \\
\hline Leite natural & 0,03 & $-0,01$ & 0,03 & 0,06 & 0,05 & 0,03 & $-0,07$ \\
Outros produtos agropecuários & 0,02 & $-0,01$ & 0,03 & 0,05 & 0,04 & 0,03 & $-0,09$ \\
Produtos de couro e calçados & 0,03 & $-0,05$ & 0,05 & 0,10 & 0,07 & 0,05 & $-0,22$ \\
Beneficiamento vegetal & 0,02 & 0,00 & 0,02 & 0,03 & 0,03 & 0,02 & $-0,04$ \\
Carne bovina & 0,05 & 0,02 & 0,06 & 0,09 & 0,08 & 0,07 & $-0,07$ \\
Carne suína & 0,07 & 0,02 & 0,07 & 0,11 & 0,09 & 0,07 & $-0,07$ \\
Carne de aves abatidas & 0,04 & 0,03 & 0,04 & 0,06 & 0,05 & 0,04 & $-0,01$ \\
Óleo vegetal refinado & 0,01 & $-0,01$ & 0,01 & 0,02 & 0,02 & 0,01 & $-0,05$ \\
Outros alimentos e bebidas & 0,04 & 0,01 & 0,04 & 0,07 & 0,05 & 0,04 & $-0,06$ \\
\hline
\end{tabular}

Fonte: Dados da pesquisa.

A variação percentual das exportações está diretamente ligada à variação do preço do produto. As exportações de milho aumentam em todos os estados, variando entre 5\% no Paraná, e ultrapassando os 30\% em Santa Catarina. Convém relembrar que $99 \%$ do milho é exportado pela região Sul, e o aumento na variação das exportações de milho, no Paraná, ocorre devido à elevação do nível de atividade do setor em outras regiões.

Com a não adoção de milho Bt11 no Paraná, o aumento no nível de atividade observado no setor de milho no Brasil é de apenas $2,4 \%$, enquanto no cenário I esse aumento era de 7,7\%. Com a adoção de milho Bt11 no Paraná, alguns produtores reduzem a produção de soja para plantar milho. Ao optarem apenas pela lavoura convencional de milho, o que se observa é a preferência por outras culturas, reduzindo em 3,7\% o nível de atividade no setor de milho na região.

Com isso, os setores de suínos, aves vivas e químicos diversos são os mais prejudicados. Inclusive para o setor de químicos diversos é preferível a adoção de milho Bt11 no Paraná, mesmo com redução na quantidade utilizada de inseticida por unidade produzida, visto que a redução na produção, no caso da 
não adoção, não compensa a maior utilização de produtos químicos na lavoura convencional.

O setor de suínos possui o segundo maior crescimento no nível de atividade, pois é o que utiliza, percentualmente, mais milho. O setor de suínos do Mato Grosso é o mais favorecido com a não adoção de milho Bt11, aumentando em 1,93\% o nível de atividade, enquanto no cenário I, a alta é de $1,23 \%$. No entanto, a pequena redução no nível de atividade do setor de suínos na região Sul representa muito, uma vez que $73 \%$ da produção se concentra nessa região.

No setor de aves vivas, o maior aumento no nível de atividade ocorre em Goiás $(1,47 \%)$, contra $1,07 \%$ no cenário anterior. Em geral, os setores com as maiores altas no nível de atividade estão localizados na região Centro-Oeste. Apesar de essa região ter um valor total de produção de milho e setores a jusante inferior ao do Paraná, estes são muito importantes para a economia do CentroOeste, representando $15,5 \%$ do PIB da região.

Ao aumentar o nível de atividade em um setor, torna-se necessária uma quantidade maior de insumos e fatores primários. $\mathrm{O}$ quanto a mais deve ser utilizado é regulado no modelo por uma função Leontief (demanda de fatores diretamente proporcional ao nível do produto). A substituição entre os fatores primários (terra, capital e trabalho) ocorre por meio de uma função CES. Como a quantidade de terra é fixa no fechamento, apenas as quantidades utilizadas de trabalho e capital variam por região. Dessa forma, uma variação no nível de atividade afeta diretamente o nível de emprego.

No setor de milho, regiões que não adotaram, ou adotaram uma pequena taxa de milho Bt11, perderam competitividade e reduziram o nível de atividade, gerando aumento no desemprego. Por outro lado, regiões que adotaram o milho Bt11 tornaram-se mais competitivas, aumentaram o nível de atividade no setor e reempregaram parte dos empregados demitidos.

O Paraná, ao adotar milho Bt11 (cenário I), economiza em torno de $16 \%$ dos custos com mão de obra (Tabela 1). Todavia, o aumento no nível de atividade é de $21 \%$ e, com isso, o setor acaba tendo elevação de $2 \%$ na quantidade de empregos. Ao se optar apenas pela cultura convencional, não há redução de emprego num primeiro momento, porém, o custo de produção fica superior aos outros estados que adotam o milho Bt11, e o setor acaba reduzindo o nível de atividade, gerando desemprego de $4 \%$ em longo prazo.

Portanto, considerando-se que o Paraná não adote milho Bt11, observa-se que tanto a mão de obra quanto os estoques de capitais se deslocam de outras regiões brasileiras para o Centro-Oeste. Mesmo assim, ainda é possível observar aumento do PIB e do consumo na região Sul. Porém, no Paraná, não apenas o setor de milho, como também os de aves e outros setores a jusante da cadeia produtiva do milho, perdem competitividade, reduzindo o nível de atividade, a quantidade de emprego e o consumo das famílias. Assim, observa-se que 
Impactos Econômicos da Introdução do Milho Bt11 no Brasil: uma abordagem de equilíbrio geral inter-regional

o Paraná apresenta redução no PIB, visto que esses setores possuem grande representatividade econômica para a região.

Nesse sentido, ao analisar o cenário II, pode-se imaginar quanto o Brasil pode ter perdido de competitividade nos últimos 10 anos, se comparado a países como os EUA e a Argentina, que passam a utilizar o milho GM. Isto pode incorrer em perdas para produtores e consumidores, além de prejudicar a criação de postos de trabalho em virtude da redução do nível de atividade econômica.

\section{Considerações finais}

Os efeitos da introdução do milho Bt11 nas lavouras brasileiras são amplos e distribuem-se de forma desigual entre os setores e regiões interligadas no modelo utilizado, devido às diferenças observadas na distribuição espacial da atividade econômica no território brasileiro.

A inovação tecnológica realizada a partir da introdução do milho Bt11 reduz os custos de produção no setor de milho e nos demais elos da sua cadeia produtiva a jusante, principalmente aves e suínos. Dessa forma, os efeitos ao longo da sua cadeia são significativos, pois elevam o nível da atividade econômica, gerando emprego em diversos estados, em especial nas regiões Sul e Centro-Oeste, que são mais dependentes destas atividades. O benefício do progresso tecnológico na agricultura, portanto, é repassado para os demais segmentos da cadeia de comercialização, que também se beneficiam dele. Este é um efeito de equilíbrio geral, que não pode ser captado por meio de modelos de equilíbrio parcial.

De maneira geral, ao adotar milho Bt11, observa-se redução na quantidade de mão de obra utilizada no próprio setor. Contudo, os setores a jusante da cadeia produtiva do milho, motivados pela redução no custo dos insumos, elevam o nível de atividade e de emprego. Com isso, em regiões onde a produção de suínos, aves, ração e beneficiamento vegetal é economicamente significativa, o desemprego causado pela introdução do milho Bt11 é compensado pelo aumento do nível de atividade destes setores.

A redução nos preços dos alimentos, proporcionada pela inovação tecnológica, milho Bt11, associada ao aumento no salário real médio eleva a renda real das famílias, possibilitando aumentar o consumo real em todas as regiões, exceto no Norte do País, em que se observa uma pequena redução. Vale ressaltar que, na região Nordeste, apesar da redução no PIB e no emprego, o consumo das famílias aumenta devido à queda no preço dos alimentos que direta ou indiretamente, consomem milho.

Por fim, no atual contexto de comercialização do milho GM no Brasil e no mundo, uma lei que proíbe seu cultivo em apenas um estado pode gerar consequências negativas, como a redução no nível de atividade, saída de 
capital, desemprego e baixa no consumo das famílias e nas exportações. Essas consequências são intensificadas quando a região possui maior dependência de produtos agroindustriais inter-relacionados na cadeia produtiva do milho, como aconteceria se o Paraná tivesse conseguido proibir o cultivo no estado.

Apesar de algumas regiões terem difícil acesso à inovação tecnológica proposta, devido à baixa renda dos produtores, proibir o uso em todo o território implica perdas ainda maiores. Como o milho GM já está liberado, cabe ao governo criar políticas públicas, viabilizando o acesso em regiões em que a produtividade do milho é relativamente baixa, como no Norte e no Nordeste do Brasil, de forma que a distribuição dos benefícios seja mais homogênea entre os estados brasileiros.

Finalmente, ressalta-se que o governo deve garantir o direito de escolha do consumidor, e, portanto são muitas as tentativas de diferenciar não só o produto como a cadeia de produtos convencionais e GM. No entanto, tal distinção ainda não é fácil e exigiria recursos consideráveis para rastrear e fiscalizar todo o processo produtivo e de comercialização. Apenas quando essa distinção estiver disponível, será possível saber o quanto os consumidores estão dispostos a pagar a mais pelo produto convencional e se isso será economicamente viável para os produtores.

\section{Referências Bibliográficas}

BORCHGRAVE, R. Cientista belga defende transgênicos para o Brasil. CIB, São Paulo, 2 ago. 2002. Disponível em: <http://www.cib.org.br/em_dia.php?id=10>. Acesso em: 1 maio 2008.

BRASIL. Ministério das Relações Exteriores. Departamento de Promoção Comercial. Brazil Trade Net. Disponível em: < http://www.braziltradenet.gov. br/>. Acesso em: 4 abr. 2008a.

Secretaria de

Ministério do Desenvolvimento, Indústria e Comércio Exterior.

CONFEDERAÇÃO DA AGRICULTURA E PECUÁRIA DO BRASIL - CNA. Participação do agronegócio no PIB volta a crescer. 19 mar. 2008. Disponível em: <http://www.cna.org.br/site/noticia.php?n=19301>. Acesso em: 23 ago. 2008.

COMPANHIA NACIONAL DE ABASTECIMENTO- CONAB. Série Histórica: produção brasileira de milho - 1977-2008. Brasília, 2008. Disponível em: <http:// www.conab.gov.br/conabweb/index.php?PAG=131>. Acesso em: 3 maio 2008.

DOMINGUES, E. P.; MAGALHÃES, A. S.; FARIA, W. R. Infraestrutura, crescimento e desigualdade regional: uma projeção dos impactos dos investimentos do programa de aceleração do crescimento (PAC) em Minas Gerais. Pesquisa e planejamento econômico (PPE). v. 39, n. 1. Abr. 2009. 
Impactos Econômicos da Introdução do Milho Bt11 no Brasil: uma abordagem de equilíbrio geral inter-regional

ELBEHRI, A.; MACDONALD, S. Estimating the impact of transgenic Bt cotton on west and central Africa: a general equilibrium approach economic research service. Washington: USDA, 7 Jul. 2004.

FACHINELLO, A.L. Avaliação do impacto econômico de possíveis surtos da gripe aviária no Brasil: uma análise de equilíbrio geral computável. 2008. 160 p. Tese (Doutorado em Ciências) - Escola Superior de Agricultura "Luiz de Queiroz", Universidade de São Paulo, Piracicaba, 2008.

FANCELLI, A.L. Benefícios da utilização do milho geneticamente modificado MON810 resistente às lagartas do cartucho (Spodoptera frugiperda), colmo (Diatraea saccharalis) e espiga (Helicoverpa zea) nos diferentes segmentos da cadeia produtiva no Brasil. In: CONGRESSO BRASILEIRO DE ENTOMOLOGIA, 19., 2002, Manaus. Resumos... Manaus: INPA, 2002, p. 161.

FERREIRA FILHO, J.B.S.; ROCHELLE, T.C.P.; ALVES, L.R.A. Avaliação dos impactos da introdução do milho GM na cadeia de comercialização do milho no Brasil. Piracicaba: Cepea. jan. 2007. 120 p.

FERREIRA FILHO, J.B.S. Uma matriz de insumo produto para o Brasil em 2001. 2006. Comunicação pessoal.

FERREIRA FILHO, J.B.S. (Coord.) ALVES, L. R. A.; ZILLI, J. B.; OSAKI, M.; BALLAMINUT, C. E. C.; RIBEIRO, R. G. Avaliação da economicidade potencial da utilização de milho geneticamente modificados da Syngenta Seeds no Brasil. Piracicaba: Editora, Abr. 2008. 34 p.

GRUÈRE, G.; BOUËT, A.; MEVEL, S. Genetically modified food and international trade. International Food Policy Research Institute, Washington, n. 00740, Dez. 2007.

GUIMARÃES, V.; CANZIANI, J.R.F.; WATANABE, M. Cadeia produtiva do milho. Curitiba: Universidade Federal do Paraná, Departamento de Economia Rural e Extensão, 2005. 108 p.

HAREAU, G.G. Transgenic rice in Asia: a general equilibrium assessment of potential welfare effects and regional distribution. 2006. 145 p. Tese (Doutorado em Filosofia: Economia, Agricultura e Ciências Sociais) - Virginia Polytechnic Institute and State University, Blacksburg, 2006. Disponível em: < http://scholar. lib.vt.edu/theses/available/etd-06212006-141903/>. Acesso em: 4 abr. 2008.

HORRIDGE, M.; MADDEN, J.; WITTWER, G. The impact of the 2002-2003 drougth on Australia. Journal of Policy Modeling, New York, v. 27, n. 3, p. 85-308, Apr. 2005.

INSTITUTO BRASILEIRO DE GEOGRAFIA E ESTATÍSTICA - IBGE. Censo agropecuário: 1970-2006. Rio de Janeiro, 2007. Disponível em: <http://www.ibge. com.br>. Acesso em: 4 mar. 2008. 
. Produção agrícola municipal. Rio de Janeiro, 2008. Disponível em: <http://www.ibge.com.br>. Acesso em: 16 ago. 2008.

JAMES, C. Global review of commercialized transgenic crops: 2002. Feature - Bt Maize. ISAAA Briefs, ISAAA: Ithaca, NY, n. 29, 2003a. Disponível em: < http:// www.isaaa.org >. Acesso em: 24 abr. 2008.

. Global status of commercialized transgenic crops: 2007. ISAAA Briefs, ISAAA: Ithaca, NY, n. 37, 2007. Disponível em: < http://www.isaaa.org>. Acesso em: 24 abr. 2008.

PAMBUDI, D.D. Regional strategies to attract investment: using a computable general equilibrium model of Indinesia. 2005. 157 p. Thesis (Doctor of Philosophy) - Faculty of Business and Economics, Monash University, Melbourne, 2005.

PARANÁ. Lei n.14162, de 27 de outubro de 2003. Veda o cultivo, manipulação, importação, industrialização e comercialização de organismos geneticamente modificado (OGMs). Diário Oficial, Curitiba, 27 out. 2003. n.6592. Disponível em: < http://celepar7cta.pr.gov.br/SEEG/sumulas.nsf/319b106715f69a4b03256efc006 01826/28205472bda1685703256e9900692ad9?OpenDocument>. Acesso em: 15 set. 2008.

SANTOS, C.V. dos. Política tributária, nível de atividade econômica e bem-estar: lições de um modelo de equilíbrio geral inter-regional. 2006. 139 p. Tese (Doutorado em Economia Aplicada) - Escola Superior de Agricultura "Luiz de Queiroz", Universidade de São Paulo, Piracicaba, 2006. Disponível em: < http://www. teses.usp.br/teses/disponiveis/11/11132/tde-10052006-152813/>. Acesso em: 4 maio 2008. 